\title{
Xylaropyrone, a new $\gamma$-pyrone from the endophytic fungus Xylaria feejeensis MU18
}

\author{
Ratklao Siriwach ${ }^{1}$, Hiroshi Kinoshita ${ }^{1}$, Shigeru Kitani ${ }^{1}$, Yasuhiro Igarashi ${ }^{2}$, Kanokthip Pansuksan ${ }^{3}$, \\ Watanalai Panbangred ${ }^{3}$ and Takuya Nihira ${ }^{1,4}$
}

The Journal of Antibiotics (2011) 64, 217-219; doi:10.1038/ja.2010.160; published online 22 December 2010

Keywords: endophytic fungus; Thai medicinal plant; xylaropyrone; Xylaria; $\gamma$-pyrone

Novel bioactive compounds have been intensively screened to identify their potential benefit in many fields of human life, including medicine, agriculture and industry. Natural compounds have been a continuous and important source of bioactive compounds, and have led to the discovery of not less than 200000 bioactive compounds so far, ${ }^{1}$ accounting for more than $50 \%$ of new medicines registered as anticancer, antibacterial, antifungal and antiviral agents during the period of 1981-2006. ${ }^{2}$

Fungal endophytes are defined as filamentous fungi that reside in the tissues of living plants without exerting any pathogenic effects. Judging from the fact more than one endophyte often inhabit a single plant, new and interesting endophytic microorganisms are likely to be found from the nearly 300000 plant species, which inhabit the diverse environments and ecosystems of the earth. ${ }^{3}$ Moreover, considering that a great number of secondary metabolites with diverse chemical structures and various biological activities ${ }^{6-8}$ have been discovered from endophytes, endophytes can be regarded as a rich source of bioactive natural products. ${ }^{4,5}$

Thailand is located in a tropical zone with abundant biodiversity and bioresources, suggesting that Thai endophytic fungi may be a rich source of bioactive compounds. A series of recent discoveries of novel bioactive substances, such as xylariaquinone A, scopararanes A and $\mathrm{B}, 11$-hydroxymonocerin, phomoenamide, phomonitroester and deacetylphomoxanthone $\mathrm{B}$, have confirmed the usefulness of fungal endophytes from Thai medicinal plants as promising bioresources. ${ }^{9-12}$

In this study, novel compounds were screened from the endophytic fungus Xylaria feejeensis MU18, isolated from Eryngium foetidum Linn., a medicinal plant in Thailand. From the crude extract, one novel compound was isolated and its chemical structure was determined. The compound possesses a novel chemical structure comprising a $\gamma$-pyrone with a hydroxymethyl group and a methylpentyl group at C-2 and C-5, respectively. This is the first report of a natural or even a synthetic compound possessing a $\gamma$-pyrone moiety having these two side chains.

\section{MATERIALS AND METHODS}

General experimental procedures

The UV spectrum was recorded on a Hitachi U-3200 spectrophotometer (Hitachi Ltd., Tokyo, Japan). NMR spectra were recorded on a on a JEOL JNM-ECS400 (JEOL, Tokyo, Japan) at $400 \mathrm{MHz}$. The ${ }^{1} \mathrm{H}$ and ${ }^{13} \mathrm{C}$ chemical shifts were referenced to the solvent signal $\left(\delta \mathrm{H} 7.26\right.$ and $\delta \mathrm{C} 77.0$ in $\left.\mathrm{CDCl}_{3}\right)$. HRFABMS was recorded on a JEOL JMS-700 spectrometer. Optical rotation was measured on a JASCO P-1020 polarimeter (Jasco, Tokyo, Japan). IR spectra were recorded on a FTIR-8400S (Shimadzu, Kyoto, Japan).

\section{Microorganism}

The endophytic fungus MU18 was isolated from leaves of Eryngium foetidum Linn., obtained from Mahidol University, Bangkok, Thailand. The fungus was identified as $X$. feejeensis based on the DNA sequences of the internal transcribed spacer (ITS) ribosomal RNA region (DNA data bank of Japan (DDBJ) accession number AB569622). A Genbank search for similar ITS sequences confirmed that the fungus was $X$. feejeensis, with $99 \%$ sequence identity. ${ }^{13}$ The fungus was deposited as X. feejeensis MU18 at the culture collection of International Center for Biotechnology (ICBiotech; Osaka University, Osaka, Japan).

\section{Fermentation and isolation}

All chemicals, media and reagents were purchased from Wako (Osaka, Japan) unless stated otherwise. For seed culture preparation, the mycelia of $X$. feejeensis MU18 grown on a potato dextrose agar slant was inoculated into $5 \mathrm{ml}$ of medium two (soluble starch $5 \%$, Pharmamedia $2 \%$, oatmeal $0.5 \%, \mathrm{KH}_{2} \mathrm{PO}_{4}$ $0.35 \%, \mathrm{Na}_{2} \mathrm{HPO}_{4} 0.25 \%$ and $\left.\left(\mathrm{NH}_{4}\right)_{2} \mathrm{SO}_{4} 0.6 \%\right)$ in test tubes $(\varnothing 12.5 \mathrm{~mm} \times$ $10.5 \mathrm{~cm}$ ), and incubated for 3 days at $28^{\circ} \mathrm{C}$ on a reciprocal shaker at 120 r.p.m. The seed culture $(2 \mathrm{ml})$ was inoculated into $100 \mathrm{ml}$ of medium two in $500-\mathrm{ml}$ baffled flasks and cultivated for 21 days at $28^{\circ} \mathrm{C}$ under a static condition.

After cultivation, culture broth $(100 \mathrm{ml} \times 10$ flasks $)$ was mixed with an equal amount of EtOAc and left to stir for $1 \mathrm{~h}$ at room temperature. Mycelia were removed by filtration with Miracloth (Calbiochem, La Jolla, CA, USA), and the EtOAc layer was recovered from a separation funnel, dried over anhydrous $\mathrm{Na}_{2} \mathrm{SO}_{4}$ and evaporated to afford a crude extract (brown gum, $650 \mathrm{mg}$ ).

${ }^{1}$ International Center for Biotechnology, Osaka University, Suita, Osaka, Japan; ${ }^{2}$ Biotechnology Research Center, Toyama Prefectural University, Imizu, Toyama, Japan; ${ }^{3}$ Department of Biotechnology, Faculty of Science, Mahidol University, Bangkok, Thailand and ${ }^{4}$ MU-OU Collaborative Research Center for Bioscience and Biotechnology, Faculty of Science, Mahidol University, Bangkok, Thailand

Correspondence: Professor T Nihira, International Center for Biotechnology, Osaka University, 2-1 Yamadaoka, Suita, Osaka 565-0871, Japan.

E-mail: nihira@icb.osaka-u.ac.jp

This is a part of the doctoral dissertation of RS.

Received 21 July 2010; revised 10 November 2010; accepted 18 November 2010; published online 22 December 2010 
The crude extract (200 mg each) was at first separated on a $\mathrm{C}_{18}$ cartridge (Sep-Pak Vac $35 \mathrm{cc}$; Waters, Milford, MA, USA) by stepwise elution with increasing $\mathrm{MeOH}$ concentrations $\left(\mathrm{MeOH} / \mathrm{H}_{2} \mathrm{O}=2: 8,4: 6,6: 4,8: 2\right.$ and 1:0 v/v). The $60 \% \mathrm{MeOH}$ fractions containing compound 1 were combined and evaporated ( $50 \mathrm{mg}$ from two repeats). The compound 1 was further purified by preparative reversed-phase $\mathrm{C}_{18}$ HPLC (PU-1570; Jasco, equipped with a UVIDEC-100-V detector) using a CAPCELL PAK C 18 column (UG80S5; Shiseido, Tokyo, Japan) with a shallow MeOH gradient in $0.1 \%$ TFA (a $60-75 \%$ $\mathrm{MeOH}$ gradient over a period of $20 \mathrm{~min}$ ) to yield $10 \mathrm{mg}$ of pure compound $\mathbf{1}$.

\section{Antimicrobial assay}

The minimum inhibitory concentration of xylaropyrone (1) was determined by a twofold broth microdilution method in three individual experiments according to the procedures of the Clinical and Laboratory Standards Institute for antimicrobial, anti-yeast and antifungal activity. ${ }^{14}$ Kojic acid was used as a reference for the $\gamma$-pyrone compound. The minimum inhibitory concentration is defined as the lowest concentration of the compound at which there is no visible growth of the indicator strains: Escherichia coli ATCC 25922, Pseudomonas aeruginosa ATCC 27853, Staphylococcus aureus ATCC 29923, Enterococcus faecalis ATCC 29212, Saccharomyces cerevisiae ATCC 6275, Candida albicans OUT 6266, Aspergillus niger ATCC 6275, Rhizopus oryzae ATCC10404 and Candida candidum IFO4598.

Xylaropyrone (1) was obtained as a yellow oil. The molecular formula was determined to be $\mathrm{C}_{12} \mathrm{H}_{18} \mathrm{O}_{3}$ on the basis of HRFABMS (obs. $m / z 211.1335[\mathrm{M}+\mathrm{H}]^{+}$, calcd. 211.1334 for $\mathrm{C}_{12} \mathrm{H}_{19} \mathrm{O}_{3}$ ), ${ }^{1} \mathrm{H}$ and ${ }^{13} \mathrm{C}$ NMR spectra data (Table 1 ). The IR spectrum showed a broadened $\mathrm{OH}$ absorption band at $3390 \mathrm{~cm}^{-1}$.

${ }^{1} \mathrm{H}$ NMR data of 1 showed two methyl signals at $\delta 0.82(\mathrm{t}, J=6.9 \mathrm{~Hz}$, $3 \mathrm{H})$ and $0.85(\mathrm{~d}, J=6.9 \mathrm{~Hz}, 3 \mathrm{H})$, eight methylene protons at $\delta 1.14$ (ddq, $J=7.6,15.0,11.0 \mathrm{~Hz}, 1 \mathrm{H}), 1.31(\mathrm{~m}, 1 \mathrm{H}), 1.41(\mathrm{~m}, 1 \mathrm{H})$, 1.61(dddd, J=6.7, 7.6, 13.4, 16.6 Hz, 1H), $2.48(\mathrm{~m}, 2 \mathrm{H})$ and $4.42(\mathrm{~s}$, $2 \mathrm{H})$, one methine proton at $\delta 1.33(\mathrm{~m}, 1 \mathrm{H})$ and two aromatic protons at $\delta 7.74(\mathrm{~s}, 1 \mathrm{H})$ and $6.20(\mathrm{~s}, 1 \mathrm{H})$ (Supplementary Figure $\mathrm{S} 1)$. The ${ }^{13} \mathrm{C}$ NMR spectrum of 1 indicated one carbonyl carbon at $\delta 180.4$, two quaternary carbons at $\delta 126.8$ and 171.4, two methyl carbons at $\delta 11.2$ and 18.3, four $s p^{3}$ methylene carbons at $\delta 29.1,31.3,33.4$ and 58.3, one $s p^{3}$ methine carbon at $\delta 33.8$ and two $s p^{2}$ methine carbons at $\delta 113.4$ and 152.4 (Supplementary Figure S2).

Three partial structures of $\mathbf{1}$, namely, a hydroxymethyl group, a methylpentyl group and a 2,5-disubstituted $\gamma$-pyrone, were deduced by comprehensive interpretation of its ${ }^{1} \mathrm{H},{ }^{13} \mathrm{C}$ NMR, COSY, hetero- nuclear single quantum correlation (HSQC) and HMBC spectra and other spectroscopic data (Figure 1). The observed carbon signals at $\delta$ $113.4,126.8,152.3,171.4$ and 180.4 in the ${ }^{13} \mathrm{C}$ NMR spectrum suggested the presence of a $\gamma$-pyrone moiety. ${ }^{15}$ This was further supported by the maximum UV absorption at $252 \mathrm{~nm}$ and strong absorption band at $1660 \mathrm{~cm}^{-1}$ in the IR spectrum. ${ }^{15}$

The key long range connections of $\mathrm{H}-8(\delta 2.48)$ with $\mathrm{C}-2(\delta 171.4)$ and $\mathrm{C}-3(\delta$ 113.4) and of $\mathrm{H}-7$ ( $\delta$ 4.42) with C-4 $(\delta$ 180.4), C-5 $(\delta$ $126.8)$ and C-6 ( $\delta$ 152.4) indicated that the hydroxylmethyl and methylpentyl groups were connected to C- 5 and C- 2 of the $\gamma$-pyrone nucleus, respectively. Regarding the absolute configuration at C-10, it was deduced to be $R$, from the comparison of optical rotations on compounds having similar aliphatic chain with 3-methyl or 3-hydroxymethyl group: those of R-configuration were all minus ((R)-2-(3-(hydroxymethyl)pentyl)-4H-pyran-4-one $\left([\alpha]_{\mathrm{D}}^{20}-0.567\right)$, $(R)$-(3-methylpentyl)benzene $\left([\alpha]_{\mathrm{D}}^{25}-5.52\right),(R)$-4-methylhexan-1-ol $\left([\alpha]_{\mathrm{D}}^{20}-8.1\right),{ }^{16-18}$ whereas those of S-configuration were all plus. ${ }^{19-21}$ Thus, the structure of 1 was elucidated as (R)-5-(hydroxymethyl)2-(3-methylpentyl)-4H-pyran-4-one (Figure 2).

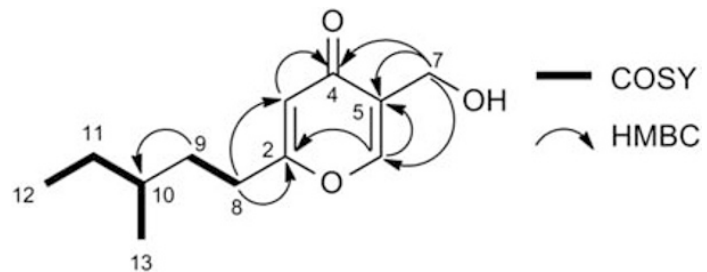

Figure $1 \mathrm{COSY}$ and $\mathrm{HMBC}$ correlation of xylaropyrone (1).<smiles>CC[C@H](C)CCc1cc(=O)c(CO)co1</smiles>

Figure 2 Structure of xylaropyrone (1).

Table 1 NMR spectroscopic data of xylaropyrone (1) in $\mathrm{CDCl}_{3}$

\begin{tabular}{|c|c|c|c|c|}
\hline Position & $\delta_{C}$ & $\delta_{H}$ & $H-H C O S Y$ & $H M B C$ \\
\hline 2 & 171.4 & - & & $\mathrm{H}-3, \mathrm{H}-6, \mathrm{H}-8$ \\
\hline 3 & $113.4 \mathrm{CH}$ & $6.20(\mathrm{~s})$ & & $\mathrm{H}-8$ \\
\hline 4 & 180.4 & - & & $\mathrm{H}-3, \mathrm{H}-6, \mathrm{H}-7$ \\
\hline 5 & 126.8 & - & & $\mathrm{H}-3, \mathrm{H}-6, \mathrm{H}-7$ \\
\hline 6 & $152.4 \mathrm{CH}$ & $7.74(\mathrm{~s})$ & & $\mathrm{H}-7$ \\
\hline 7 & $58.3 \mathrm{CH}_{2}$ & $4.42(s)$ & & $\mathrm{H}-6$ \\
\hline 8 & $31.3\left(\mathrm{CH}_{2}\right)$ & $2.48(\mathrm{~m})$ & $\mathrm{H}-9$ & $\mathrm{H}-3, \mathrm{H}-9$ \\
\hline \multirow[t]{2}{*}{9} & $33.4\left(\mathrm{CH}_{2}\right)$ & $1.41(\mathrm{~m})$ & $\mathrm{H}-8, \mathrm{H}-9$ & $\mathrm{H}-8, \mathrm{H}-10, \mathrm{H}-12, \mathrm{H}-13$ \\
\hline & & 1.61 (dddd, J=6.7, 7.6, 13.4, $16.6 \mathrm{~Hz}$ ) & $\mathrm{H}-8, \mathrm{H}-9$ & \\
\hline 10 & $33.8(\mathrm{CH})$ & $1.33(\mathrm{~m})$ & $\mathrm{H}-11, \mathrm{H}-13$ & $\mathrm{H}-9, \mathrm{H}-11, \mathrm{H}-12, \mathrm{H}-13$ \\
\hline \multirow[t]{2}{*}{11} & $29.1\left(\mathrm{CH}_{2}\right)$ & $1.14(\mathrm{ddq}, J=7.6,15.0,11.0 \mathrm{~Hz})$ & $\mathrm{H}-10, \mathrm{H}-12$ & $\mathrm{H}-9, \mathrm{H}-10, \mathrm{H}-12, \mathrm{H}-13$ \\
\hline & & $1.31(\mathrm{~m})$ & $\mathrm{H}-10, \mathrm{H}-12$ & \\
\hline 12 & $11.2\left(\mathrm{CH}_{3}\right)$ & $0.82(\mathrm{t}, J=6.9 \mathrm{~Hz})$ & $\mathrm{H}-11$ & $\mathrm{H}-11$ \\
\hline 13 & $18.8\left(\mathrm{CH}_{3}\right)$ & $0.85(\mathrm{~d}, J=6.9 \mathrm{~Hz})$ & $\mathrm{H}-10$ & $\mathrm{H}-9, \mathrm{H}-10, \mathrm{H}-11$ \\
\hline
\end{tabular}


To the best of our knowledge, xylaropyrone, which consists of a $\gamma$-pyrone moiety, a hydroxymethyl group and a methylpentyl group, is a novel compound that has not previously been identified in natural resources or derived from chemical synthesis.

Xylaropyrone (1): a yellow oil; $[\alpha]_{\mathrm{D}}^{26}-4.1$ (c 0.10, MeOH); UV $(\mathrm{MeOH}) \lambda_{\max }(\log \varepsilon) 215$ (3.48), 252 (3.85); HRFABMS $m / z[\mathrm{M}+\mathrm{H}]^{+}$ 211.1335 (calcd. for $\mathrm{C}_{12} \mathrm{H}_{19} \mathrm{O}_{3}, 211.1334$ ). IR $v_{\max }$ (film) 3161-3502 $(\mathrm{OH}), 2958,2523,2858,1654(\mathrm{C}=\mathrm{O}), 1596,1419,1338,1184,1128$ and $1029 \mathrm{~cm}^{-1} .{ }^{1} \mathrm{H}\left(\mathrm{CDCl}_{3}, 400 \mathrm{MHz}\right),{ }^{13} \mathrm{C}\left(\mathrm{CDCl}_{3}, 100 \mathrm{MHz}\right), \mathrm{H}-\mathrm{H}$ COSY and HMBC see Table 1.

As no antimicrobial data is available on a $\gamma$-pyrone compound possessing two side chains, especially to evaluate the effect of two side chains on a $\gamma$-pyrone on biological activities, the antimicrobial activities against typical prokaryotes and eukaryotes were measured using kojic acid as a reference. Xylaropyrone showed moderate activity against $S$. cerevisiae (minimum inhibitory concentration $=32 \mu \mathrm{g} \mathrm{ml}^{-1}$ ), whereas kojic acid did not show any inhibition even at a concentration of $128 \mu \mathrm{g} \mathrm{ml}^{-1}$. Neither xylaropyrone nor kojic acid showed any inhibitory activity against E. coli, $P$. aeruginosa, S. aureus or E. faecalis when used at a concentration of $512 \mu \mathrm{g} \mathrm{m}^{-1}$, or against A. niger, $R$. oryzae or C. candidum when administered at $128 \mu \mathrm{g} \mathrm{ml}^{-1}$.

\section{ACKNOWLEDGEMENTS}

This study was supported in part by a scholarship from the Ministry of Education, Culture, Sports, Science and Technology (MEXT) of Japan to RS and by a grant for a 'Research Project in the Field of Biotechnology' from MEXT, the National Research Council of Thailand and the National Science and Technology Development Agency of Thailand to TN, HK and SK.

1 Bérdy, J. Bioactive microbial metabolites. J. Antibiot. 58, 1-26 (2005).

2 Newman, D. J. \& Cragg, G. M. Natural products as sources of new drugs over the last 25 years. J. Nat.Prod. 70, 461-477 (2007)

3 Strobel, G. A. Endophytes as sources of bioactive products. Microbes Infect. 5, 535-544 (2004).
4 Guo, B., Wang, Y., Sun, X. \& Tang, K. Bioactive natural products from endophytes: a review. Appl. Biochem. Micro. 44, 136-142 (2008).

5 Suryanarayanan, T.s. et al. Fungal endophytes and bioprospecting. Brit. Mycol. Soc. 23, 9-19 (2009).

6 Schulz, B., Boyle, C., Draeger, S., Römmert, A. K. \& Krohn, K. Endophytic fungi: a source of novel biologically active secondary metabolites. Brit. Mycol. Soc. 106, 996-1004 (2002)

7 Tan, R. X. \& Zou, W. X. Endophytes: a rich source of functional metabolites. Nat. Prod. Rep. 18, 448-459 (2001).

8 Zhang, H. W., Song, Y. C. \& Tan, R. X. Biology and chemistry of endophytes. Nat. Prod. Rep. 23, 753-771 (2006).

9 Tansuwan, S. et al. Antimalarial benzoquinones from an endophytic fungus, Xylaria sp. J.Nat.Prod. 70, 1620-1623 (2007).

10 Pongcharoen, W., Rukachaisirikul, V., Phongpaichit, S., Rungjindamai, N. \& Sakayaroj, J. Pimarane diterpene and cytochalasis derivatives from the endophytic fungus Eutypella scoparia PSU-D44. J.Nat.Prod. 69, 856-858 (2006).

11 Sappapan, R. et al. 11-Hydroxymonocerin from the plant endophytic fungus. Exserohilum rostratum. J.Nat.Prod. 71, 1657-1659 (2008).

12 Rukachaisirikul, V., Sommart, U., Phongpaichit, S., Sakayaroj, J. \& Kirtikara, K. Metabolites from the endophytic fungus Promopsis sp. PSU-D15. Phytochemistry 69, 783-787 (2008).

13 Hsieh, H. M. et al. Phylogenetic status of Xylaria subgenus Pseudoxylaria among taxa of the subfamily Xylarioideae (Xylariaceae) and phylogeny of the taxa involved in the subfamily. Mol. Phylogenet. Evol. 54, 957-969 (2010).

14 Clinical and Laboratory Standards Institute (CLSI). 2007. (a) Methods for dilution antimicrobial susceptibility tests for bacteria that grow aerobically-seventh edition; approved standard M07-07, (b) Reference method for broth dilution antifungal susceptibility testing of yeasts-third edition; approved standard M27-A3 (c) Reference method for broth dilution antifungal susceptibility testing of filamentous fungi-second edition; approved standard M38-A2, Wayne, PA.

15 Hosoe, T. et al. Lepidepyrone, a new $\gamma$-pyrone derivative, from Neolentinus lepideus, inhibit hyaluronidase. J. Antibiot. 60, 388-390 (2007).

16 Crimmins, M. T. \& O'Mahony, R. Synthesis of spiroketals: a general approach. J. Org. Chem. 55, 5894-5900 (1990).

17 Levene, P. A. \& Harris, S. A. Maximum rotations of carboxylic acids containing a phenethyl group. J. Biol. Chem. 110, 725-733 (1935).

18 Reiss, T. \& Breit, B. A unified strategy for the stereospecific construction of propionates and acetate-propionates relying on a directed allylic substitution. Chem. Eur. J. 15, 6345-6348 (2009)

19 McCabe, R. W., Parri, O. L. \& Price, A. H. Synthesis and mesophase formation of branched-chain bis-1,2 dithiolatonickel (II) complexes. J. Mater. Chem. 3, 609-613 (1993).

20 Ishmuratov, G.Yu., Yakovleva, M. P., Ganieva, V. A., Amirkhanov, D. V. \& Tolstikov, G. A. $\mathrm{L}-(-)-$ Menthol in the synthesis of key synthons for optically active methyl-branched insect pheromones. Chem. Nat. Comp. 41, 719-721 (2005).

21 Barrett, A. G. M., Pena, M. \& Willardsen, J. A. Total synthesis and structural elucidation of the antifungal agent papulacandin D. J. Org. Chem. 61, 1082-1100 (1996)

Supplementary Information accompanies the paper on The Journal of Antibiotics website (http://www.nature.com/ja) 